\title{
EDUCAÇÃO CONTRA OS QUADROS DE GUERRA
}

\author{
Fernando Guimarães Oliveira da Silva (UEMS)* \\ https://orcid.org/0000-0002-5428-2870
}

\section{RESUMO}

Este texto é um ensaio no campo da filosofia da educação, e que faz parte do projeto de pesquisa Contribuições da interseccionalidade com as diferenças para se problematizar o saber-fazer docente, desenvolvido junto à Universidade Estadual de Mato Grosso do Sul (UEMS). Como objetivo, é proposto problematizar o compromisso ético-político da educação a serviço da desconstrução do favorecimento dos quadros de guerra, proposto pelo enfoque butleriano, naturalmente propagados, na atualidade, contra as diferenças. Com abordagem no terreno das pesquisas pós-críticas em educação, a pesquisa bibliográfica se fez exploratória e descritiva a fim de evocar pesquisadores(as) da educação para revigorar o projeto-compromisso ético-político brasileiro em prol da educação escolar pública e democrática. Na atualidade, são criados, a exemplo do atual governo, o fomento aos quadros de guerra, por meio de intensos discursos de ódio às diferenças de gênero, sexualidades, raça, etnias etc., o que reacende a luta por uma educação que resista às guerras.

Palavras-chave: educação; quadros de guerra; diferenças.

\section{ABSTRACT}

\section{EDUCATION AGAINST WAR FRAMEWORKS}

This text is an essay in the field of philosophy of education, it is part of the research project, Contributions of intersectionality with the differences to problematize the teaching know-how, developed with the State University of Mato Grosso do Sul (UEMS). As an objective, it is proposed to problematize the ethical-political commitment of education in the service of deconstructing the favoritism of war frameworks, proposed by the Butlerian approach, naturally propagated, nowadays, against the differences. Based on post-critical research in education, the bibliographical research was exploratory and descriptive in order to evoke education researchers to reinvigorate the Brazilian ethical-political commitment to public and democratic school education. Today, the current 
government is fomenting war frameworks, through intense hate speeches about differences in gender, sexuality, race, ethnicity etc., which rekindles the struggle for an education that resists wars.

Keywords: education; war frameworks; differences.

\section{RESUMEN \\ EDUCACIÓN CONTRA MARCOS DE GUERRA}

Este texto es un ensayo en el campo de la filosofía de la educación, es parte del proyecto de investigación, Contribuciones de la interseccionalidad con las diferencias para problematizar los conocimientos docentes, desarrollado con la Universidad Estatal de Mato Grosso do Sul (UEMS). Como objetivo, se propone problematizar el compromiso ético-político de la educación al servicio de la deconstrucción de los marcos de guerra propuestos por el enfoque de Butler, propagado naturalmente, hoy en día, contra las diferencias. Con un enfoque en el campo de la investigación poscrítica en educación, la investigación bibliográfica se volvió exploratoria y descriptiva para evocar a los investigadores en educación a revitalizar el compromiso brasileño de ética y política del proyecto a favor de la educación escolar pública y democrática. Hoy en día, se crea la promoción de cuadros de guerra, siguiendo el ejemplo del gobierno actual, a través de intensos discursos de odio a las diferencias de género, sexualidad, raza, etnia que reaviva la lucha por una educación que se resiste a la guerra.

Palabras-clave: educación; imágenes de guerra; diferencias.

\section{Introdução}

Em 2017, o Professor Fernando Penna participou de mesa, no VSimpósio Internacional de Educação Sexual (SIES), ${ }^{1}$ junto à Universidade Estadual de Maringá (UEM). Penna (2017) palestrou com o título de Discussões sobre a escola sem partido (ESP) e suas repercussões no espaço escolar. Com um olhar muito desconfiado, algo me chamou a atenção: o debate sobre a educação democrática.

À época, com a entrada recente no curso de doutorado em educação daquela Universidade, assustadoramente vi-me frente a um debate que acreditava que estava ultrapassado. Cheguei, inclusive, a descredibilizar a mesa guiada por Penna (2017). No entanto, conforme ele destacava os porquês da necessária reatualização do debate, senti-me consumido por

1 O V SIES, que teve como tema "Saberes/Trans/Versais currículos identitários e pluralidades de gênero", é um evento coordenado pela Profa. Dra. Eliane Rose Maio, por meio do NUDISEX da UEM. uma vibração extremamente obscurantista. 0 projeto inicial do Programa Escola sem Partido (ESP) prevê implicitamente um projeto obscurantista de educação, o que me levou a observar, enquanto estudante de educação básica e ensino superior de cidades pequenas no interior de Mato Grosso do Sul (MS), entre 2000 e 2010, ${ }^{2}$ que o debate em torno do assunto do obscurantismo não se fazia presente. Por outra via, notava que em grandes centros urbanos, como no caso do Rio de Janeiro, apresentado por Penna (2017), a proposta se propagava descontroladamente.

Nos diferentes níveis educacionais de minha trajetória educacional, observei que a formação pluralista que tive para debater sobre questões sociais, culturais, ambientais, econômicas etc. de modo crítico corria o risco de não fazer

2 Período de formação do autor que compreende o 6o ano do Ensino Fundamental e a conclusão do Ensino Superior, em curso de Licenciatura. 
mais sentido. Como docente, acredito que um elemento central para dar profissionalidade às práticas de ensino é a liberdade de ensinar para transgredir a ordem normativa que tanto combate a resistência, nos mesmos termos de Paulo Freire (1987) e Bell Hooks (2019).

Enquanto professor, à época - e também no presente -, o pensamento que comparece para caracterizar o momento é de que forças ultraneoliberais e ultraconservadoras atacam a autonomia docente em diferentes etapas de especialização da organização do trabalho pedagógico. Transpor a memória de meu doutoramento para a atualidade me fez observar que, naquele momento, apesar de ter visto o retorno do debate da educação democrática como novidade, forças políticas ultraconservadoras estavam arquitetando as bases de alicerce para que o atual governo, Jair Bolsonaro, pudesse efetivar tal primado.

O Programa ESP reflete o projeto societário do atual governo ultraneoliberal, encontra suas bases existenciais no discurso de ódio que desqualifica o humano e não se preocupa com as pessoas, tampouco com a educação; como reflexo disso, na mesma medida do ESP temos a educação domiciliar e a militarização das escolas. Fica visível que, para a educação, o financiamento será mínimo e baseado num projeto perigoso de privatização porque a escola pública não é relevante para a economia.

Os sentidos que os agentes ultraneoliberais lançam questionam as políticas de redução da desigualdade, caracterizando-as como privilégios dos direitos humanos para "vagabundos". Intensamente compartilham com os vetores sociais de extrema direita uma variabilidade de lugares públicos que radicalmente desqualificam o humano em benefício do capital. Pessoas que não têm vergonha de escancarar o seu ódio fundacionalista religioso e racista com defesas antigêneros, antirraça, antidiferenças.

Os agentes supramencionados se juntam para compartilhar de uma agenda de ódio às diferenças que encontra explicação para existir no bojo da autoridade moral supostamente dita por vias religiosas: os chamados ultraneoconservadores. Cotidianamente, esses agentes se sentem autorizados(as) a deslegitimar os grupos minoritários atingidos historicamente pela precariedade, negando, por sua vez, as desigualdades evidentes no terreno das classes sociais.

Não mais como docente da educação básica, hoje, observo que o debate ético-político por uma educação pública, laica e democrática se faz no ensino superior, na formação de professores(as). No âmbito da formação inicial, observo que o compromisso é propiciar experiências científicas para o descolamento de leituras superficiais da realidade que têm sido amplamente divulgadas e autorizadas no atual governo. E, no contexto da formação contínua em serviço, aos/às poucos(as) professores(as) que dão crédito ao espaço das universidades como um local significativo para desconstrução de pensamentos do senso comum e obscurantistas.

Com a mesma força do ódio com que as perspectivas ultraneoconservadoras remam contra as diferenças, ${ }^{3}$ objetivo problematizar o compromisso sociopolítico da educação com a redução dos quadros de guerra criados tão naturalmente na atualidade. Para isso, procuro na perspectiva butleriana a viabilidade para combater os quadros de guerra que são legitimamente autorizados pelos componentes do novo projeto extremista de direita do atual governo.

Este texto faz parte do projeto de pesquisa Contribuições da interseccionalidade com as diferenças para se problematizar o saber fazer docente (2019-2021) (SILVA, 2021), ${ }^{4}$ coordenado por mim, junto à Universidade Estadual de

3 A compreensão de diferenças que é tratada neste texto encontra sentido nos estudos de Richard Miskolci (2005). 0 autor caracteriza que os estudos da diferença avançam desterritorializando-se de perspectivas naturalistas e essencialistas que a transposição do darwinismo trouxe para se pensar pessoas e sociedades. Destaca que os estudos da diferença foram possíveis em razão de três correntes marcantes: 1) os feminismos; 2) os estudos de gênero; 3 ) os estudos sociológicos e culturais voltados para a compreensão das diferenças.

4 O referido projeto de pesquisa não possui financiamento. 
Mato Grosso do Sul (UEMS). Com o enfoque das pesquisas pós-críticas em educação, proponhome a utilizar da pesquisa bibliográfica com o viés descritivo e exploratório para abordar a educação contra os quadros de guerra no interior de uma concepção de escola democrática. O uso do enfoque pós-crítico permite lidar com pressupostos e premissas que auxiliam na interrogação da realidade educacional a partir da criação ou rupturas com os quadros de guerra.

Para Marlucy Paraíso (2014, p. 34), o uso de pressupostos e premissas nos permitem questionar os sistemas de referências tidos como universais e passar a incluir modelos existenciais da diferença: "Podemos com esses pressupostos deixar-nos guiar pelas novas maneiras de compreender, ver, dizer, sentir e ouvir criadas e instauradas pelas aprendizagens que tivemos das diferentes correntes das teorias pós-críticas." E acrescenta:

Com tais aprendizagens ficamos armados/as, emocionados/as, encorajados/as. Uma coragem necessária para, em nossas metodologias, encontrarmos saídas contra o aprisionamento e a fixidez de sentidos, os essencialismos, o 'é isso' ou o 'deve-se fazer assim'. Esses pressupostos nos mobilizam porque sabemos que, ao partirmos para pesquisar em educação, precisamos, acima de tudo, buscar/encontrar/perseguir novos modos de enunciação do currículo e da educação. (PARAÍSO, 2014, p. 34).

É com esse senso pesquisador de desconstruções que se orienta a compreensão de uma educação contra os quadros de guerra. Os recursos utilizados para a pesquisa bibliográfica foram a pesquisa exploratória e descritiva. Segundo Antônio Gil (2008, p. 27), a exploratória é realizada para proporcionar uma visão geral e aproximativa acerca de um assunto: "Este tipo de pesquisa é realizado especialmente quando o tema escolhido é pouco explorado e torna-se difícil sobre ele formular hipóteses precisas e operacionalizáveis." Sob o enfoque descritivo, a pesquisa se propõe a descrever as "[...] características de determinada população ou fenômeno ou o estabelecimento de relações entre variáveis" (GIL, 2008, p. 28).
A estrutura deste ensaio foi organizada para apresentar: a) os quadros de guerra na perspectiva butleriana; b) a educação pública democrática como um local em que as práticas de ensino oportunizam acesso a uma educação que desconstrua sistemas de hierarquização, normalização, diferenciação, desigualdades e classificação de pessoas; c) debates emergentes para se pensar a educação contra os quadros de guerra.

\section{Os quadros de guerra}

Aqui, pretendo apresentar ensaios butlerianos a respeito da vida e da ética, para, então, entender como são criados os processos de humanização e desumanização nas guerras que podem ser travadas no tempo presente. Em Vida precária: os poderes do luto e da violência, Judith Butler (2019) enuncia sobre a manipulação que diferentes vetores sociais fazem com o poder de decidir, quais vidas serão vistas como perdidas e quais serão massacradas com a precariedade ${ }^{5}$ e a vulnerabilidade. Ao debater sobre as formas convencionais que somos inquiridos(as) a pensar sobre os processos de humanização e desumanização, Butler (2019) diz que há corpos-existências facilmente representados e outros que não são vistos como humanos.

Os corpos-existências humanizados podem ser vistos como aqueles que estão enquadrados no terreno do reconhecido, o que dispensa qualquer tipo de esforço para justificá-los. Em contrapartida, o elemento diferença define a criação do corpo-existência tido como desumanizável. Pensar os processos de humanização e desumanização nos leva a crer que há instâncias que fomentam certos sentidos que agem na manutenção desses processos.

5 Butler (2015a, p. 31) aponta o conceito de precariedade: "Afirmar que uma vida pode ser lesada, por exemplo, ou que pode ser perdida, destruída ou sistematicamente negligenciada até a morte é sublinhar não somente a finitude de uma vida (o fato de que a morte é certa), mas também sua precariedade (porque a vida requer que várias condições sociais e econômicas sejam atendidas para ser mantida como uma vida)." 
Assim, essa autora utiliza-se dos estudos de Emmanuel Levinas acerca do rosto para entender como são consolidados os processos de humanização e desumanização. Nos estudos de Levinas, Butler (2019, p. 163) relata que o rosto não é necessariamente a dimensão física da face humana, mas o rosto é representado como uma cena de vocalização do outro em mim: "[...] o rosto parece ser uma espécie de som, o som da linguagem esvaziando seu sentido, o substrato sonoro da vocalização que precede e limita o recebimento de qualquer sentido semântico".

No sentido da abordagem butleriana, é notória a materialização do outro como uma existência exterior a mim que me cobra responsabilidade com a sua vida. Butler (2019) utiliza como exemplo para fundamentar o reflexo do outro na minha vida o ensinamento religioso: não matarás. Remete ao que essa autora compreende como vida precária, o fato de minha vida estar lançada na responsabilidade dos outros, dando autonomias para que eles pensem sobre a possibilidade de se responsabilizarem por minha vida ou não.

Caímos, assim, na dimensão ética da responsabilidade pela preservação da vida do outro. Este outro traz expressões culturais, sociais, políticas que nos dão condições de representá -lo em um lugar no espaço-tempo. Quando não consideramos validar tais expressões desse outro, consequentemente nossas atitudes tornam a imagem desse outro precária, justificando, assim, o emprego de uma variabilidade de instrumentos que invalidam que ele possa existir diferente de uma moldura predeterminada. Demanda, então, pensar a ética.

Em Relatar a si mesmo: crítica à violência ética, Butler (2015b) utiliza dos estudos de Nietzsche e Foucault para se aprofundar nas relações entre as normas e as pessoas a fim de conhecer como somos constituídos. É nesse contexto que essa autora percebe que as relações entre os sujeitos e as normas acontecem por meio de cenas de interpelação. 0 sujeito se constrói em meio a um conjunto de normas sociais que produzem regimes de verdades. Ao relatar a si mesmo, o sujeito é interpelado por normas sociais, sendo levado a reconhecer e se responsabilizar por si e pelas outras pessoas a partir dessas normas.

Segundo essa autora, o ato de apreender um corpo como uma existência possível não significa que se produziu o reconhecimento. 0 que fica certo, na sua compreensão, é que estamos localizados(as) no interior de uma normatividade que é acionada toda vez que me relaciono com as outras pessoas. Desse modo, Butler (2015b) confirma que ao relatarmos nós mesmos aos outros para nos fazermos existências possíveis, não fazemos isso de forma original, mas fazemos interpelações às normas sociais.

Quando o outro se apresenta para mim, e seu corpo é construído diferente do que as cenas de interpelação social pressionam como as únicas existências possíveis, estou diante de outras cobranças. A interação com os outros acontece frente a uma série de pressões internas e externas; no âmbito interno, pensar este outro pode ser feito a partir da interpelação com a norma social e, no âmbito externo, este outro resistiu às normas.

Nesse sentido, Butler (2015b) entende que o reconhecimento de si ocorre por limitação de um regime de verdade que decide quais formas existenciais serão possíveis de serem reconhecidas e quais não serão. Todavia, essa autora admite que isso não significa que o regime de verdade estabelece o quadro forçoso de como devo me reconhecer. Evidentemente que o quadro é uma referência existencial de normas para o ser, e a partir dele as normas de reconhecimento são governadas, disputadas e revisadas.

Fica patente a relação de interdependência que temos em referência aos outros, e a violência ética, nesse caso, acontece quando a experiência de responsabilidade para com a vida do outro se torna frágil, obviamente porque a conduta ética não é transparente. Paralelo ao ato ético para com a vida do outro, tenho a responsabilidade por reconhecê-lo. Impõe pen- 
sar, então, a responsabilidade ética para com a vida que não está no contexto dos quadros de referência do ato de reconhecimento.

No tempo presente, posso conhecer que a vida diferente existe, mas não a reconhecer como vivível. Nos termos de Butler (2015a), conhecer e reconhecer são atos diferentes, uma vez que conhecer significa que a vida está ali e não altera a sociedade para mantê-la; já o reconhecer significa dar manutenção para a vida vista como possível. Entender que o reconhecimento não atinge certas vidas nos traz uma série de questionamentos acerca dos porquês se retroalimentam tanto ódio em relação às diferenças.

0 peso da responsabilidade ética me invade quando não sinto que certas vidas podem ser vividas. Estamos diante de um conflito que é a associação entre duas questões que parecem opostas, mas Butler (2015b) consegue teorizar as relações que complementam o conceito de violência ética. Butler (2015b) destaca que a ética não é transparente e racional, porque no processo de constituição da vida em sociedade somos moldados(as) no mesmo nível que nossas autonomias dentro dos enquadramentos de vidas reconhecidas como vivíveis.

Sob este olhar, Butler (2015b) indica que ser ético equivale a pensar criticamente a formação social das normas que nos interpelam. Significa que é preciso questionar o universo de referência existencial da norma para sentir-se engajado(a) na condução do ato ético. 0 ato ético também pode representar um ato de violência se ele costumeiramente se produz invisibilizando certos enquadramentos existenciais das diferenças.

Butler (2015b) diz que o ato ético é uma violência no momento em que a norma social decide como devo ser, ferindo a afirmação de minha identidade pessoal. Isso permite afirmar que a ética também é dependente do regime social, ainda que nela o/a sujeito acredite que $o$ discurso é originário de si: "Nossa 'incoerência' define o modo como somos constituídos na relacionalidade: implicados, obrigados, deriva- dos, sustentados por um mundo social além de nós e anterior a nós" (BUTLER, 2015b, p. 87).

Dito isso, para narrar o que sou não é preciso coerência porque o discurso é opaco, mas precisa ser feito em menção ao conjunto de referência que a norma impõe. Para impor de forma autocrítica, elemento fundamental no relato de si que a própria autora indica, será preciso passar pelo risco. Na concepção dessa autora, dialogar a partir de questionamentos com as regras normativas que definem quem eu posso ser é um risco, porque compromete o reconhecimento que os outros fazem de mim.

Nesse processo relacional com o outro, há uma reciprocidade de reconhecimento. 0 elemento ético, nesse sentido, é um compromisso de transposição das normas para se jogar no risco que é afrontar os esquemas de inteligibilidade que a norma criou. 0 sujeito, nesse caso, passa por um processo de despossessão da coerência do eu para desconstruir-se com o objetivo de invocar uma nova moldura existencial.

Caímos, no entanto, nos processos de reconhecimento que firmam corpos existenciáveis por meio de enquadramentos aceitos como humanamente possíveis ou outros como desumanos. Os vetores que instituem enquadramentos para os corpos-existências tidos como possíveis de serem humanizados e desumanizados decidem os quadros de apreensão, condições de aparição e reconhecimento. A motivo de problematizar: qual enquadramento de corpo-existência enderecei meu ser? Ele é capturado pela normatividade ou ele é um corpo-existência atingido pela definição de desumanizado?

É um problema relevante para assim considerar como os quadros de guerra referentes ao meu corpo-existência são criados nos contextos das instituições sociais. Para isso, vejamos o que Butler (2019) enuncia sobre os enquadramentos, as condições de aparição e reconhecimento para entender como as vozes do Outro que estão dentro de mim me perquirem internamente a fazer em relação à matança ou à paz. 
Em Quadros de Guerra: quando a vida é passível de luto?, Butler (2015a) afirma que não há vida nem morte sem relação com um enquadramento, mas essa autora caracteriza que o enquadramento nem sempre é total e determinístico, porque toda vez que o enquadramento tenta normatizar uma moldura existencial tida como plena, as rupturas produzem vazamentos.

Os processos de humanização da vida são baseados nas formas como os corpos-existências são enquadrados dentro de formas normativas. Essas formas normativas de enquadramento buscam assegurar validade no bojo de explicações tradicionais, com forte enfoque na religiosidade e no fundacionalismo biológico. Corpos-existências mapeados como brancos, heterossexuais, classe média, religioso, casado com o sexo oposto, com filhos etc., toda essa normatividade eurocêntrica representa o enquadramento normativo.

Molduras que vazam tal enquadramento experimentam o peso da desumanização, por isso requer entender como essas normas criadas operam no sistema de reconhecimento para tornar sujeitos mais fáceis e difíceis de serem reconhecidos. Com isso, propor compreender como as normas de reconhecimento são forjadas e em que termos são possíveis de serem mudadas para acolher outras molduras.

Os esquemas normativos são interrompidos um pelo outro, emergem e desaparecem dependendo das operações mais amplas de poder, e com muita frequência se deparam com visões espectrais daquilo que alegam conhecer. Assim, há sujeitos que não reconhecíveis como sujeitos e 'há' vidas que dificilmente - ou, melhor dizendo, nunca - serão reconhecidas como vidas. (BUTLER, 2015a, p. 17).

Um enquadramento normativo não consegue encontrar fontes de explicação para sua existência se não tiver uma moldura diferente. 0 conhecimento da existência de outra moldura pode ser justificado para entender que existem outras possibilidades de apreensão do corpo-existência. A figura de moldura diferente corrói as normas de reconhecimento que foram criadas para estabelecer formas inteligíveis para ser um corpo-existência, e tal vacilo impõe que no interior da norma se cria atos de conhecimento que expulsam a diferença, e no exterior preocupa-se com a transposição das barreiras.

O fato de os corpos-existências diferentes eclodirem na sociedade não significa que usufruem de formas de reconhecimento. Eles apenas participam de momentos de aparição, são apenas apreendidos, mas as condições para serem reconhecidos demandam entender como as redes de poder gerenciam pertencimento, responsabilidade e a distribuição da perda e da comoção pública da vida.

Nas palavras de Butler (2015a), cumpre entender que reivindicações sociais e políticas de corpos-existências desumanizados não têm direito à ampliação da vida e da capacidade de sobrevivência. Os enquadramentos desumanizados das diferenças demandam a construção de uma nova ontologia corporal que exige: “[...] repensar a precariedade, a vulnerabilidade, a dor, a interdependência, a exposição, a substância corporal, o desejo, o trabalho e as reivindicações sobre a linguagem e o pertencimento social" (BUTLER, 2015a, p. 15).

No tempo presente, pensar em uma nova ontologia corporal para o enquadramento exige remar contra a maré do pensamento ultraneoconversador, que eclode com muita força nas tendências políticas que potencializam o ódio. Sabendo das atuais condições brasileiras, vêse que a política de criação dos quadros de guerra é realizada a todo momento quando os discursos de ódio são facilmente proliferados sem tanta problematização porque se tem um governo que autoriza e legitima isso.

No entanto, urge resgatar uma compreensão do rosto levinasiano para entender como ele é criado para armar os discursos de ódio para o ataque às diferenças. Isso se faz necessário para entender a hostilidade contra grupos historicamente sobreviventes nos terrenos da precariedade (negros(as), mulheres, indígenas, 
lésbicas, gays, bissexuais, travestis e transexuais, povos tradicionais e outros).

Butler (2019) diz que os discursos que predominam nos sistemas de representação, sejam odiosos ou não, expressam o rosto dos processos de humanização ou desumanização sobre os grupos das diferenças. A crítica, nesse caso, reside na tarefa científica de problematizar o rosto da humanização; afinal, aqueles(as) que conseguem se autorrepresentar são os chancelados pelos processos de humanização, mas temos aqueles(as) que não e que são considerados(as) menos humanos.

A não humanização de pessoas diferentes e seus grupos faz com que elas não existam e, com isso, suas demandas ficam invisibilizadas e apagadas do cenário público onde as decisões são debatidas. Butler (2019) destaca que a mídia tem sido um local de produção da desumanização de rostos diferentes. Para isso, essa autora usa o exemplo da instrumentalidade midiática realizada em torno do rosto de terror, associando-o com Osama Bin Laden, Yasser Arafat e Sadan Hussein.

Essa autora compreende que eles são enquadrados em uma moldura de desumanização, inclusive com um esforço dos próprios sujeitos em destaque. Butler (2019, p. 172) enfatiza: "Esses retratos da mídia são muitas vezes manejados a serviço da guerra, como se o rosto de Bin Laden fosse o próprio rosto do terror, como se Arafat fosse o rosto da mentira, como se o rosto de Hussein fosse o rosto da tirania contemporânea." Convém entender como são manejados os quadros de guerra em nível brasileiro, uma vez que estamos diante de um contexto político em que muitos discursos de ódios são proliferados deliberadamente.

0 trabalho de instrumentalização do rosto da humanização e da desumanização acontece constantemente no interior dos conflitos de guerra. Pode-se dizer que há para além do trabalho próprio dos sujeitos citados para a produção do rosto do terror; há também o fortalecimento dessa imagem por parte do outro lado que é afetado. Nesse caso, o lado norte-americano, que usa a cultura desses sujeitos para considerá-la retrógrada e não aberta à globalidade do desenvolvimento capitalista.

Nesse sentido, os quadros de guerra afetam a organização interna da manutenção da cultura e a coloca como algo negativo para o mundo. Propõe pensar o rosto, nesse processo, em relação às perdas, os sofrimentos, o luto, a comoção e a agonia da vida. Todos os rostos que são afetados pelos quadros de guerra expressam uma ameaça: o terror, o medo ao diferente, a força dos países situados na dimensão do norte global, perda de identidade dos países não capitalistas etc.; vários processos criam rostos diferenciados, podemos nos identificar ou não com a materialização deles.

No manejo dos rostos que representam a desumanização e a humanização, precisamos ficar atentos para o que, de fato, quem enuncia sobre esses rostos pretende representar. É preciso desconfiar de suas intenções. A ideia, nesse sentido, é a de pensar o manejo dos rostos a favor das políticas de guerras contemporâneas no contexto brasileiro em relação aos rostos que compõem grupos que se situam no terreno das diferenças. Notamos, com isso, que as guerras não são firmadas por meio de um conflito bélico, mas também discursivo, que precarizam as vidas de sujeitos diferentes para a morte.

Dois eventos chamam a atenção para viabilizar um terreno analítico sobre a política de criação dos quadros de guerra: 1) notícia sobre as fakes news, publicada em 2019 por um site de ampla abrangência; b) discursos do ex-ministro da Educação, Abraham Weintraub, e da ministra da Mulher, Família e Direitos Humanos, Damares Alves.

A primeira notícia, veiculada pelo site Brasil de Fato, publicada em abril de 2019, evidencia os discursos das fakes news mais propagadas durante o período de pleito eleitoral de 2018, com o título "Neste $1^{\text {o }}$ de abril, relembre nove fake news que marcaram o cenário político do Brasil":

1) Kit gay e livro exibido por Bolsonaro no Jornal Nacional; 2) Mamadeira de piroca; 3) Jean Willys: ministro de Haddad; 4) Frase de 
Haddad sobre decisão do Estado sobre crianças; 5) Agressão de Ciro Gomes a Patrícia Pilar;

6) Marielle Franco ligada a facção criminosa;

7) Manuela D'ávila com a camiseta 'Jesus é Travesti'; 8) Aposentadora de Bolsonaro por insanidade; 9) Obras de Fátima Bernardes na casa do homem que esfaqueou Bolsonaro; 10) Senhora agredida por ser eleitora de Bolsonaro (RODRIGUES, 2019).

Há dois pontos que veiculam a formação de quadros de guerra na notícia acima: 1) a questão do gênero e da sexualidade contidas nos itens de 1 a 4 e no item 7 ; 2) complementando o primeiro, a condução das massas para se oporem aos projetos de governança do partido oposto.

Analisar teoricamente o que se propõe às questões do gênero e da sexualidade não são o foco da proposta deste estudo. Usá-los para evidenciar a presença de um quadro de guerra vem de encontro ao uso feito pelos(as) representantes das políticas de extrema direita acerca dos ataques ultraneoconservadores que realizam sobre as temáticas de gênero e sexualidades para justificar a autoridade moral que veiculam, principalmente por meio do discurso pró-família, antigêneros e contrários aos direitos humanos.

Em relação ao segundo evento para entender a política dos quadros de guerra, optou-se por apresentar um evento recente no Estado brasileiro. Trata-se de reunião ministerial, ocorrida em 22 de abril de 2020, que teve quebra de sigilo autorizada pelo Ministro Celso de Mello do Supremo Tribunal Federal (STF). A divulgação desta reunião ocorreu porque o ex-ministro, Sérgio Moro, alegou interferência do Presidente Bolsonaro em investigações da Polícia Federal (PF).

Os quadros de guerra em análise advêm dos discursos proferidos pelos(as) ministros(as) à época, Sr. Abraham Weintraub, que ocupava o Ministério da Educação, e da atual Ministra da Mulher, Família e Direitos Humanos, a Sra. Damares Alves.

A Ministra Damares inicia sua fala, por sinal, muito surpresa, afirmando que, no nosso país, sua gestão encontrou um milhão e trezentos mil ucranianos(as) com cultura extremamente intacta, ou como bem retrata a ministra, preservada. Mais surpresos(as) ficamos nós, em ter que escutar que não havia quaisquer dados sobre povos tradicionais, como se isso fosse culpa de governos anteriores, aos quais ela não tinha vínculo.

Damares traz, em sua fala, a diferença de forma mais evidente, e ainda retrata a representação de ciganos, indígenas, pessoas idosas, mulheres vítimas de violência, seringueiros etc. Considerando a diversidade cultural (tratemos dessa como a principal, mas certos(as) de que existem outros elementos da diversidade), há que se ressaltar que se tratam de identidades sociais que, na transposição de suas existências à brasilidade, muito ainda precisam conquistar em matéria de direitos humanos. No entanto, o manejo do quadro de guerra no discurso de Damares visa tratar isso como deslegitimado. Evidentemente, ao propor o discurso ultraneoconservador pró-vida e pró-família, o qual, aliás, expressa tão somente a sua opinião, a ministra Damares não representa a concepção de diferentes grupos pertencentes às identidades étnico-raciais circunscritas à sua fala inicial. Vidas no interior destes grupos são apagadas diariamente com a violência policial e militarização das questões sociais, porém, a ministra se interessa apenas por preservar vidas, aquelas que, para ela, logicamente são humanizadas vivíveis porque estão dentro dos enquadramentos da autoridade moral.

Muito preocupada com a cultura de diferentes povos, a Ministra enfatiza que muitas crianças estão vivendo e crescendo com essas pessoas, o que pode ser um problema. Em referência a isso, a Ministra Damares acredita que essas culturas diversificadas não são passíveis de serem preservadas porque não se enquadram no modelo pró-vida e pró-família predominante em sua concepção.

Na sequência do discurso de Damares, temos do ex-ministro Weintraub. Este, por sua vez, afirma, em seu pronunciamento, a desle- 
gitimação cultural de povos que compõem o que ele entende por "povo brasileiro". Segundo o ex-ministro, não há povos indígenas, povos ciganos, há patrioticamente a ideia de "povo brasileiro".

Odeio o Partido Comunista. Ele está querendo transformar a gente numa colônia. Odeio o termo 'povos indígenas', odeio esse termo. Odeio. Os 'povos ciganos'. Odeio! Só tem um povo nesse país, quem quer, quer, e quem não quer, segue de ré. Só tem um povo, pode ser preto, pode ser branco, pode ser japonês, pode ser descendente de indígena, mas tem que ser brasileiro. Acabar com esse negócio de povos e privilégios. Só pode ter um povo, não pode ter Ministro que acha que é melhor que o povo, que o cidadão. Isso é um absurdo! [...] A gente veio aqui para acabar com tudo isso, não para manter essa estrutura. (VÍDEO..., 2020).

Um discurso com muitos elementos para entender os quadros de guerra que Weintraub maneja à instrumentalidade de seu discurso. Com uma leitura patriota do povo brasileiro, ele desconsidera a legitimidade de povos específicos que contribuem para identificar esse povo brasileiro. A ideia de supremacia racial invade seu discurso para desqualificar grupos subalternos que não estão presentes.

Podemos encontrar dois pontos de manejo dos quadros de guerra quando Weintraub afirma: 1) Estamos conversando com quem deveríamos lutar; 2) Não estamos sendo duros com os privilégios. Diz, ainda, que acha um absurdo o fato de ser o único que tem muitos processos éticos junto à Comissão da Presidência, mas não é de assustar, novamente, que isso esteja acontecendo com ele dada a dimensão de seus discursos racistas e propagadores de ódio.

Weintraub manipula o discurso de ódio em referência às diferenças, mas para lapidar a crueldade que soa os efeitos de sentido, culpabiliza o partido dos(as) comunistas como o responsável pela sua alteração, uma vez que criaram muitos(as) privilégios às identidades culturais fragmentadas e descoladas da ideia de povo brasileiro que ele tanto divulga existir univocamente.
Trazer dois acontecimentos tão significativos do tempo presente reafirma a necessidade de discutir sobre uma proposta de educação contra os quadros de guerra no interior da educação escolar democrática e do direito à educação de grupos afetados pelas políticas do ódio resultantes das guerras firmadas.

\section{Educação pública democrática}

Carlos Cury (2002) contribuiu para pensar a educação escolar pública e democrática brasileira. Esse autor conjugou educação democrática e o direito de ser diferente associado ao direito à igualdade. Cury (2002) compreende que é papel do Estado prover a oferta de educação escolar pública gratuita com o intuito de intervir no rumo da redução das desigualdades. Nesse sentido, ele destaca que para entender o direito à educação é necessário considerar o jogo das forças sociais em conflito.

Nessa arena de conflitos, a classe dominante identificou que o Estado de direito seria um forte aliado para compensar carências sociais que afetam a população trabalhadora, e, assim, dar manutenção ao capital. Contudo, na tentativa de associar a educação escolar pública democrática com o direito à diferença e à igualdade, Cury (2002) reconhece a complexidade das demandas postas à escola contemporânea.

A complexidade, segundo Cury (2002, p. 261), se encontra nas dificuldades de eliminação das hierarquizações das diferenças e negação da igualdade, enfatizando que os diferentes autores(as) sociais sabem do poder da educação na sociedade capitalista: “[...] o direito à educação passa a ser politicamente exigido como uma arma não violenta de reivindicação e de participação política." Mais atualmente, porém, é observado que o direito à educação escolar democrática se encontra em perigo de desmantelamento.

Helena Singer (2008) se baseou nos estudos de Michael Apple e James Beane, durante a década de 1990, para abordar a gestão escolar democrática. Para isso, sua pesquisa de 
pós-doutoramento oportunizou afirmar que escolas democráticas apresentam as seguintes características: 1) gestão participativa nos processos decisórios que envolvam a comunidade escolar; 2) organização pedagógica sem currículos compulsórios, onde os estudantes definem suas trajetórias de aprendizagem; 3) as relações não hierárquicas entre estudantes e educadores (SINGER, 2008).

Singer (2008) pontua que esse modelo advém do processo de renovação pedagógica ocorrido na segunda metade do século XVIII, na Europa. Essa autora afirma que as escolas democráticas estão presentes em sociedades desenvolvidas, subdesenvolvidas ou em desenvolvimento, mas, no início dos anos 2000, têm passado pelo recrudescimento de sua proposta ligado aos seguintes pontos:

1. o desenvolvimento de novas tecnologias de comunicação que facilitam os processos de aprendizagem autônoma e a formação de comunidades de aprendizagem e de redes; 2 . as novas teorias do conhecimento que preconizam a superação do paradigma disciplinar científico por relações mais combativas e multifacetadas; 3. os avanços nas pesquisas de psicologia cognitiva em relação aos aspectos motivacionais do aprendizado; 4. as transformações no mundo do trabalho no sentido da desregulamentação das relações, da imprevisibilidade das carreiras e da multiplicidade dos caminhos profissionais; 5. o crescimento do movimento rebelde de reinvenção da democracia. (SINGER, 2008, p. 8).

Considerando a especificidade do Brasil, as escolas públicas democráticas têm o desafio de se questionar em relação ao seu compromisso sociopolítico com a inclusão social, valorização da diferença, da equidade e dos direitos humanos no âmbito da instituição escolar e, mais que isso, nas práticas de ensino dos(as) professores(as).

Gaudêncio Frigotto (2017) organizou um grupo de textos para compor obra com posicionamento contrário ao ESP, ao passo que atinge a liberdade de ensinar. Para esse autor, 0 presente projeto trata do esforço de políticas de extrema direita ultraneoconservadoras e ultra- neoliberais para liquidar a escola pública como espaço de formação humana, debates sobre os usos dos valores democráticos e libertários, 0 convívio e o respeito à diversidade.

No plano estrutural, o projeto ESP é um dos ataques realizados pela manutenção da hegemonia de poder do império da elite que se utiliza da religião católica, das mídias e dos organismos internacionais para continuar transformando a escola numa empresa a serviço do capital. É crescente o uso de Deus como mercadoria para assegurar a autoridade moral de toda montagem desse arsenal colonizador que domina todas as pessoas, criando desigualdades e violências impossíveis de serem resolvidas.

No governo do Partido dos(a)s trabalhadores(as), Frigotto (2017) ressalta que a classe dominante não aguentou abrir mão de seus lucros e privilégios, tampouco acreditar que isso estava sendo possível para pequenos(as) empresários(as). Tal evento já não estava mais suportável; afinal, estávamos há 14 anos sob transformação. Levou a maior parte dos(as) parlamentares, cerca de 90\%, a evocar Deus, a família e a pátria para justificar o impeachment da Presidente Dilma Rousseff, em 2016.

Este processo profundamente regressivo indica que a sustentação dos lucros dos grandes grupos econômicos mundiais e seus sócios locais só pode ser mantida mediante a doutrina do ajuste e da austeridade que se traduz pela ampliação da exploração do trabalhador, corte de direitos, difamação e desmanche do que é público e de políticas universais. Doutrina que, para manutenção de sua agressividade, desliza para a criminalização daqueles que se opõem e na anulação do Estado de direito e na montagem de um Estado policial. (FRIGOTTO, 2017, p. 25).

Para conter quaisquer tipos de manifestações políticas contrárias, o Estado utiliza da violência policial com a justificativa de criminalização do terrorismo. Com isso, criminaliza os movimentos sociais, culturais, sindicais e políticos que se opõem à violência, desigualdade, exclusão de direitos e do pensar divergente, justificando, ainda, o porquê a escola e o/a pro- 
fessor(a) devem ser neutros(as). No plano dos acontecimentos socioeconômicos que afetam a educação pública, é evidente o desmantelamento da área enquanto política social.

A perspectiva freireana é válida de ser pontuada no âmbito dos estudos sobre educação democrática; afinal, Paulo Freire, no início dos anos 1960 até a década de 1990, enfrentou os sistemas de dominação que objetivavam conservar e reforçar as desigualdades sociais que refletiam nas pessoas por meio de processos de desumanização.

Freire (1987), em a Pedagogia do Oprimido, denunciou um formato de organização educacional e das práticas de ensino a serviço da manutenção dos sistemas de opressão quando depositava modelos existenciais da classe dominante nos processos de vida dos(as) oprimidos(as). Reduzidas as possibilidades de ruptura com este modelo, esse autor denominou tais práticas educacionais como a educação bancária que mantém as pessoas subordinadas às estruturas capitalistas.

Numa sociedade que se deseja democrática, Freire (1987) diz que é preciso espaço para que radicalmente a participação nas instâncias de decisões aconteça para que possamos nos construir como sujeitos, homens e mulheres, interventores(as) no mundo que vivemos. Nesse sentido, precisamos ser educados(as) para fazer/ser ativos(as) no mundo, e não telespectadores(as). Freire (1987) confere ao ensino e à aprendizagem dimensões sociopolíticas, nas quais o trabalho docente não se assemelha à transmissão de conteúdo, mas cria o ambiente devidamente adequado para motivar seus/ suas alunos(as) à problematização crítica do existir, da sociedade e das relações produzidos na interação sujeito e sociedade.

Ao lidarmos com um cenário eminentemente ultraneoconservador, desponta-se que a escola tem um enfrentamento a resistir, o de manter-se democrática frente às ameaças de sua destruição. Fernando Cássio (2019) considerou na apresentação de recente obra que organizou, Educação contra a barbárie, que as ameaças são os discursos eficientistas de empresariamento da educação e as assessorias dos organismos internacionais reguladores. Retoma, na concepção desse autor, a defesa da educação como um projeto coletivo e a contraposição às agendas ultraneoliberais centradas na competitividade e as agendas ultraneoconservadoras que consagram a família tradicional.

Cássio (2019) coloca a questão da educação escolar pública como uma urgência no contexto das lutas educacionais, considerando o atual risco evidente à liberdade de ensinar. Para esse autor, a liberdade de ensinar é uma tarefa urgente para a promoção de debates acerca da educação democrática e se consolida numa prática de ensino que oferta condições de possibilidade de não regulação das autonomias das crianças e adolescentes para reproduzir um jeito único de expressar o conhecimento.

A interpretação dada à escola como espaço de educação escolar democrático refere-se à adoção de políticas de ensino e aprendizagem condutoras da experimentação científica à diferença, ao dissenso, à contra-hegemonia. Um local onde a liberdade reflete no ensino e na aprendizagem como uma fuga dos sistemas de dominação.

Inspirada nos princípios freireanos, Bell Hooks (2019) acredita que uma educação democrática se faz dentro e fora da sala de aula e deve estar distante de práticas autoritárias, visto que: "Ao atacar a educação democrática como prática de liberdade, o autoritarismo na sala de aula desumaniza e, por isso, destrói a 'magia' que está sempre presente quando os indivíduos são aprendizes ativos." (HOOKS, 2019 , p. 201). Essa autora complementa que a prática do autoritarismo tira a vontade e o gosto pelo aprender.

Hooks (2019) pontua que muitos(as) educadores(as) autoritários não abrem espaço para o diálogo e para a conversa, reduzindo seu ato educativo apenas à transmissão de conhecimentos na perspectiva de uma narrativa única. Isso faz com que as relações de ensino e aprendizagem nas escolas sejam um local de “[...] 
ensinar boas-maneiras-burguesas" (HOOKS, 2019 , p. 202). A questão da diversidade e da diferença presente em seus/suas alunos(as) passam a ser desconsideras, desvalorizadas e estilhaçadas das possibilidades de serem potencial recurso de ensino e aprendizagem. Um projeto educacional que reproduz estruturas de dominação.

Entende-se, assim, que é tarefa da educação democrática evidenciar processos de dominação e tratá-los criticamente no âmbito das metodologias de ensino e aprendizagem, visando ter conteúdo formativo que promova outras possibilidades, desvencilhadas de um existir apenas subalterno e inferiorizado. Urge pensar a educação contra os quadros de guerra.

\section{Pensar a proposta de educação contra os quadros de guerra}

Por acreditar que a dialogicidade freireana é possível em ambientes educacionais libertadores, democráticos e transgressores é que se torna possível pensar numa proposta de educação contra os quadros de guerras armados pelas políticas do ódio em relação às diferenças. Acredito que problematizar uma educação contra os quadros de guerra se faz por meio da linguagem endereçada para se pensar os sistemas de opressão e dominação. A linguagem pode manter estruturas significativas de fortalecimento das desigualdades, tratamento tendencioso para os quadros de dominação, medo e aversão às diferenças. É preciso entender a linguagem como a serviço dos quadros de guerra ou uma linguagem contrária à sua manutenção.

Butler (2019) diz que a forma como somos endereços, por certos enquadramentos existenciais impostos normais, encontram sentido no interior do discurso. Essa autora destaca que, para Levinas, o sujeito é interpelado em razão da relacionalidade com o outro. Nesse encontro relacional com o outro, o sujeito se reconhece interdependente para a sua constituição.

\section{E adiciona:}

Então, já existe certa violência em ser endereçado, receber um nome, estar sujeito a um conjunto de imposições, compelido a responder a uma rigorosa alteridade. Ninguém controla os termos pelos quais somos endereçados, pelo menos não da maneira mais fundamental. Ser endereçado é, desde o início, uma privação da vontade, e essa privação existe com base da condição do discurso. (BUTLER, 2019, p. 169).

Como se vê, os sistemas de opressão utilizam-se do discurso para justificar um tratamento desumanamente endereçado ao sujeito enquadrado fora do universo de referência humanamente aceitável. Processos de discriminação, do ódio e da violência contra as diferenças se consolidam no cenário discursivo atual e, como se viu nos estudos butlerianos, são responsáveis por retroalimentar os quadros de guerra. Em que termos a educação pode ser uma forma de desarmar os sentidos do endereçamento para os quadros de guerra?

Uma educação contra os quadros de guerra não se faz autoritária, mas se produz em desfavor do ódio e do terror que nas possibilidades conjuntas entre ultraneoliberalismo e ultraneoconservadorismo do tempo presente se vê terreno farto para efetivação. Para verificar a eficácia disso, basta abrir as redes sociais e analisar postagens curtas e longas, lives, imagens, memes; um arsenal armamentista de produção das guerras, inclusive com a indicação do governo de deixar viver e deixar morrer quando deliberam tranquilamente ameaças contra a vida. As guerras contemporâneas travadas atuam com um princípio racial, que se faz muito presente na exclusão de corpos considerados imorais, infames e desonrosos.

As guerras contemporâneas se fortalecem, de modo inicial, no contexto relacional e da linguagem, para posteriormente se fazerem presentes com o uso de objetos (facas, armas etc.) que tiram o direito à vida. Para as duas questões, o trabalho da educação reside no contexto das possibilidades de rupturas com a produção de linguagens colonizadoras, eu- 
rocêntricas e formadoras do ódio. Logo, se contribui para deslegitimar a proliferação de discursos naturalizadores das desigualdades, da violência e das inimizades.

Questionar a criação desses sistemas de opressão que criam rios de desigualdades é uma forma encontrada por Freire (1987) de educar para a liberdade. Esse autor explora no campo da educação as possibilidades de libertação em defesa de uma educação dialógica, construtora da autonomia, da consciência e a atividade na história. Isso significa que as pessoas precisam problematizar o porquê da criação dos quadros de desumanização, pensando a respeito de quem se beneficia com as políticas do ódio.

Segundo Freire (1987), o processo de libertação é coletivo. Isso significa que a libertação ocorre como um projeto formativo de professores(as) e seus/suas alunos(as), compartilhando de um projeto de resistência à lógica ultraneoconservadora que visa dominar pessoas: "A superação da contradição é o parto que traz ao mundo este homem novo, não mais opressor; não mais oprimido, mas homem libertando-se." (FREIRE, 1987, p. 36).

Freire (1987) diz que o processo de libertação acontece quando os(as) oprimidos(as) reconhecem que eles(as) não são a minoria, mas sim a maioria. Dentro do grupo oprimido há questões da diferença para serem resolvidas, mas para construir uma democracia substantiva e radical será preciso que a unidade se veja na diversidade. No interior dessa proposta, Freire (1987) pontua que a diversidade é predisposição para se aprender a conviver com as diferenças e propõe que o multiculturalismo implica vontade política, mobilização e organização de cada grupo cultural com vistas a atingir fins comuns.

0 enfoque de uma nova ética eclode para inflar o seio da construção coletiva por uma educação democrática. Uma ética que se predisponha à não violência e contrária à naturalização da formação dos quadros de guerra. Trata-se de uma forma de reconhecer novos enquadramentos existenciais das diferenças, nos quais a educação será um local em que tais corpos diferentes possam encontrar sentido para estarem em discurso e legitimarem-se possíveis de existir.

Uma educação contra os quadros de guerra propõe validar uma existência diferente. Se propõe a reconhecer a existência dos(as) negro(as), indígenas, homossexuais, lésbicas, travestis, transexuais, ucranianos(as), chineses, abrasileirados etc. Tais sujeitos são discursivamente tratados com insultos que a todo o momento produzem os quadros de guerra. Dizer sobre existências diferentes é necessário, principalmente porque muitas pessoas progressistas assinalam reconhecer os direitos humanos delas, mas, por outro lado, violentamente agem com processos de desumanização e se acham no poder de gerenciar suas mortes.

Validar as vidas diferentes pressupõe problematizar processos sócio-históricos condutores da precariedade que afetam tais vidas. Visa produzir rupturas amplamente redimensionadas para uma nova ética da não violência e da cultura de paz. Os/as professores(as) precisam se abrir para isso; afinal, estamos há dois milênios privilegiando um universo de referência cisheteronormativo, masculino, católico e de cor branca como a única maneira possível de se existir.

Nos mesmos parâmetros de Freire (1987, p. 51) com uma educação contra os quadros de guerra, é preciso crer no povo constituído de pluralidades e, para isso, suas diferenças, de modo geral, precisam ser validadas possíveis: "E crer no povo é condição prévia, indispensável, à mudança revolucionária. Uma revolução se reconhece mais por esta crença no povo, que o engaja, do que por mil ações sem ela." Há que se engajar em processos pedagógicos sociopolíticos mais equânimes para dar sentido ao compromisso educacional contra os quadros de guerra firmados.

Outro exemplo cunhado por Butler (2019) a respeito da criação dos quadros de guerra se refere ao uso da burca. Essa autora caracteriza 
que muitas pessoas pensam que a burca é um sinônimo de retrocesso cultural, atraso e resistência à modernidade, mas o uso dela tem um significado cultural relevante para a cultura islâmica. No entanto, a mídia, especialmente o New York Times, exibiu os rostos dessas mulheres sem a burca como um rosto que passava pelo ato de libertação, com uma intensa gratidão aos militares norte-americanos.

0 que foi retratado no reconhecimento do rosto das mulheres islâmicas na mídia simboliza o progresso para quem olha de fora. No entanto, quem está imerso naquela cultura observa o sofrimento do apagamento cultural em razão de uma agência mundial que vende uma figura feminina. 0 rosto fotografado das mulheres islâmicas que tiraram a burca promoveu, no sentido das perspectivas levinasianas, que não houve precarização da vida, “[...] uma vez não vimos ou ouvimos nenhuma vocalização de luto ou agonia nele, nenhum entendimento sobre a precariedade da vida" (BUTLER, 2019, p. 173).

A pergunta, então, é: seria esse rosto humanizador ou desumanizador? 0 fato de uma potência mundial invadir uma cultura para impor a sua é visto como um triunfo mundial e não como a eliminação da diferença. Nesse sentido, a imposição desse rosto é desumanizador, porque eu não fui convidado a pensar sobre a relevância dele e, no caso das jovens afegãs, é questionável se a inferioridade cultural foi em nome do feminismo ou de imposição norte-americana dos quadros de guerra para que este país aparecesse como dotado de força mundial.

Nos contextos de guerra, a apreensão representacional no rosto pode ser realizada de forma a obscurecer seu sofrimento. Butler (2019) destaca que a mídia se responsabiliza por esvaziar de humanidade certos enquadramentos existenciais que não são estabelecidos como possíveis de terem uma vida digna ou uma morte mais dolorosa. Os esquemas de inteligibilidade acerca do ser enquadrado humano e desumano produzem imagens daqueles(as) que são menos que humanos disfarçados de humanos e "[...] ameaça enganar aqueles que poderiam pensar que reconhecem um humano ali, naquele rosto" (BUTLER, 2019, p. 177).

Para evitar que os processos de desumanização ocorram violentamente é preciso evidenciar as vidas diferentes na cena pública, porque os corpos diferentes compõem as políticas da rua tornando-se públicos. Isso significa que eles existem, mas precisam estar nas avenidas públicas para serem ouvidos e mostrados o suficiente para causar provocações necessárias, porque a violência não é exposta contra vidas diferentes. Por outro lado, Butler (2019, p. 178) concorda que a "violência enquadra aquilo que é exposto".

No esforço de guerra, a violência é um mecanismo que enquadra a vida e a morte de pessoas diferentes como irrepresentáveis ou são representadas de forma deturpada ou imoral. Butler (2019) reitera, com isso, que as vidas diferentes não são sentidas como perdidas, porque antes não foram choradas, elas não são enlutáveis e isso justifica a proibição da sensação de perda ou de luto público. Significa articular o conteúdo curricular com a formação dos quadros de guerra contemporâneos em diferentes áreas do saber que compõem os currículos escolares.

Ao reivindicar a ética da não violência, Butler (2015a) conduz, a partir de perspectivas lacaniana e levinasianas, como o sujeito pode identificar nas relações com as outras pessoas um encontro consigo mesmo. No encontro com a reivindicação da não violência, Butler (2015a) considera relevante compreender que tal reivindicação não é um princípio ou uma regra aplicável, mas um apelo. Segundo essa autora, quaisquer pessoas, um dia, passaram por uma experiência violenta, até mesmo aqueles(as) que utilizam da não violência.

A violência é performada, externada e incorporada da normatividade social; além disso, ela pode ser aprendida e reproduzida tanto na relação com as outras pessoas quanto comigo mesmo. Butler (2015a) nos coloca que o uso da não violência envolve uma luta dinâmica, na qual competimos com a normatividade so- 
cial, isto é, o uso da não violência não significa purgá-la da normatividade social, tampouco descobri-la existente e por conta disso cultivar uma região ostensivamente não violenta de si, mas, ao contrário, é preciso reconhecer que estamos imersos(as) nos contextos da violência e a luta acontece quando resolvo agir com a não violência.

Para Butler (2015a), a reivindicação da não violência passa pelo questionamento: não violência contra quem? Não violência contra o quê? Tais questionamentos permitem com que pensemos a respeito do enquadramento do corpo de qual sujeito é atingido com o discurso da não violência. Isso requer compreender que se há receptividade no discurso da violência em relação a algum sujeito, “[...] então será menos fácil aceitar a violência como um fato social normal" (BUTLER, 2015a, p. 235).

Ao sermos formados(as) no interior de um conjunto de normatividades sociais, o poder expressa com violência a nossa constituição, ele nos dá condições de sermos reconhecidos(as) como corpos inteligíveis e comunica os riscos da não inteligibilidade ou da inteligibilidade parcial (BUTLER, 2015a). Retornando ao pensamento de Levinas, Butler (2019a) considera que o rosto da violência existe por conta de um impulso assassino de matança contra qual este rosto precisa ser protegido.

Como dito anteriormente, não é só por meio de conflito bélico de um país com outro que se criam as guerras. No contexto interno de um país também se cria um movimento de guerra quando se arma um discurso ultraneoconservador contra as diferenças, justificando sua consolidação por meio da natureza dos corpos. Hastear uma bandeira de guerra acontece o tempo todo quando policiais sobem ao morro e matam pessoas negras; quando travestis e transexuais são assassinadas em nome da família tradicional; quando se naturaliza o feminicídio por amor; quando se diz que a homossexualidade se cura com violência; quando do estupro corretivo de mulheres lésbicas; quando meninas e meninos pequenos são vítimas de abuso e violências sexuais intrafamiliares etc.

Sei que parece muito arriscado responsabilizar a escola pelo trabalho educativo de desconstrução das guerras que historicamente temos assistido na constituição de nosso país. Entretanto, a proposta de educação libertária das escolas democráticas representa uma possibilidade de luta contra os quadros de guerra firmados em desfavor das diferenças e nos faz pensar numa educação que humaniza corpos -existências outros.

Butler (2015a) destaca que apenas quando a vida é considerada passível de luto que a violência perde sentido. Há que se ressaltar, então, que tanto o luto como a violência têm poderes, eles permitem que asseguremos a igualdade entre os sujeitos que conduzem à ética da não violência: "Quando as normas de violência são reiteradas sem fim e sem interrupção, a não violência busca deter a iteração ou redirecioná-la de maneira que se oponha aos objetivos que a impulsionam." (BUTLER, 2019a, p. 257).

Nesse sentido, o ambiente educacional reserva a resistência de pensar a condição de apreensão e reconhecimento dos corpos que não considerados inteligíveis (negros(as), estrangeiros, LGBT+, transfronteiriços, indígenas etc.) a fim de que possam conduzir a uma ética da não violência ou a fim de problematizar os termos que enquadram os corpos supracitados como não detentores de vida possível de ser vivida. Nos termos de Butler (2019a, p. 259), "Trata-se mesmo de um modo de resistência, especialmente quando se recusa e rompe com os enquadramentos por meio dos quais a guerra é forjada repetidas vezes".

Portanto, convém retornar a Freire (1996), quando, em Pedagogia da autonomia, destaca que é preciso que a educação assegure o respeito à autonomia e à dignidade de cada um(a) como um imperativo ético, descolando-se do pensamento de que isso é um favor ou uma barganha. É por meio de práticas de ensino e aprendizagem dialógicos que crianças e adolescentes aprendem a respeitar o diferente, evitando que se tornem machistas, racistas, 
classistas a partir de explicações genéticas, sociológicas ou históricas que justificam a superioridade de uns/as em relação a outros(as).

E concluir que: "Qualquer discriminação é imoral e lutar contra ela é um dever por mais que se reconheça a força dos condicionamentos a enfrentar." (Freire, 1996, p. 67). Evidentemente que a proposta é que as práticas de ensino assumam responsabilidade com a formação de quadros de guerra contemporâneos, conformando ou rompendo com as estruturas potencializadoras dos ódios e com o não reconhecimento de certas existências.

\section{Considerações finais}

No âmbito de uma educação democrática, a perspectiva orientadora das práticas de ensino no contexto dos conteúdos curriculares precisa ser problematizada. É um questionamento que perfaz a formação dos quadros de guerra quando existências demarcadas diferentes são jogadas para o tratamento desumano. A educação tem compromisso ético-político com os movimentos de ruptura que se propõem a investigar sistemas de dominação e desconstrui-los normais/naturais.

Este ensaio faz parte de conflitos societários que refletem nos ambientes educacionais da atualidade, e nos faz pensar a educação a serviço do terror, das hierarquizações, da formação das políticas do ódio e da inimizade como expressões armamentistas dos quadros de guerra tão difundidos por forças reacionárias. Traz para o âmbito da filosofia da educação a problemática do compromisso formativo que a educação, de forma geral, e a escolar, de modo específico, assumem para as condições de vida dos(as) sujeitos-escolares.

As expressões atuais dos quadros de guerras do tempo presente requerem que pensemos a formação de um rosto sobre certos grupos sociais atingidos pela precariedade no Brasil, a fim de entender o porquê se propaga vociferadamente tanto discurso de aversão às diferenças. 0 momento impõe refletir a reatua- lização de preceitos de supremacia racial que se manifestam em situações que desumanizam vidas diferentes e as gerenciam para a morte.

0 esboço, aqui proposto, traz problematizações para se pensar a educação contra os quadros de guerra e, sobretudo, que temos responsabilidade com a condução e reprodução deles. Desse modo, não se pretende criar roteiros predispostos a serem aplicados quando o/a professor(a) entender que sua ação caminha na contramão dos direitos humanos e contribui para a ampliação do ódio às diferenças.

0 discurso de que direitos humanos são direcionados para privilegiar certos agrupamentos sociais em detrimentos da coletividade; os direitos humanos deixam as pessoas mais libertas para cometerem crimes; os direitos humanos só cobrem "vagabundos"; os direitos humanos motivam sistemas de hierarquização etc., enfim, uma série de falácias que obscurecem toda a trajetória das atrocidades historicamente utilizadas para hostilizar as diferenças do modelo padrão de corpo-existência considerado superior aos demais.

No sentido butleriano, pensar contra os quadros de guerra visa buscar a revisão da ontologia do humano. E, para a educação, a busca por essa revisão se faz no contexto do conhecimento científico como uma forma de promover acesso crítico e emancipador às explicações sobre as diferenças de gênero, de sexualidade, raça, etnia etc.

A educação contra quadros de guerra visa desconstruir formas eurocêntricas que condenaram as diferenças e disseminaram para o mundo o seu modelo como um padrão de referência de normalidade, moralidade e normatividade. Objetiva promover a valorização da diversidade cultural, a preservação da identidade cultural e os valores de direitos humanos como uma busca por equidade, justiça e pelo governo das autonomias em desfavor do ódio.

Trata-se de propor uma cultura de paz quando se pretender manejar os sentidos a favor da manutenção do terror. No Brasil, é possível observar a pretensão de retorno ao 
obscurantismo como uma proposta que tem na educação uma forma de diminuir quaisquer possibilidades de as diferenças assegurarem a possibilidade de existir.

É válido ponderar que as diferenças estão refletidas nos corpos e ocupam as avenidas identitárias, não se pode exterminá-las tão facilmente. 0 que pode ser feito é desconfigurá-las da condição de humano, o que requer de diferentes ambientes onde as diferenças se fazem presentes, o fortalecimento da área de humanas como uma forma de agir contra os quadros de guerra. Usar da educação como uma forma de transgredir dizeres do ódio para encontrar o fundamento que justifica a existência desse discurso e, a partir daí, problematizar o que ele pretende edificar ou reatualizar.

Educar contra os quadros de guerra se faz na fuga dos modelos impostos de práticas de ensino e aprendizagem. Para isso, será preciso forjar uma comunidade de ensino e aprendizagem que valoriza a transgressão e a subversão como uma forma de desconfiar dos discursos de ódio, objetivando, assim, desarmar o fenômeno do ódio ao/à professor(a) que ensina elementos das diversidades; que se preocupa com uma sociedade onde todos/todas/todes possam ter ampliadas sua capacidade de sobrevivência; onde, em meio às disputas constantes no cenário social e que refletem no ambiente escolar, possamos enaltecer a democracia.

Educar contra os quadros de guerras propõe pensar que todos os corpos importam e suas existências precisam ocupar currículos, valorizar a produção cultural que fazem e, mais que isso, questionar o porquê são alvos de matança, precarização e ódio. Há inúmeras formas de se explorar tais questões no âmbito das práticas de ensino engajadas em perspectivas democráticas, dos direitos humanos e das diferenças. É preciso permitir-se.

\section{REFERÊNCIAS}

BUTLER, Judith. Quadros de guerra: quando a vida é passível de luto? Belo Horizonte: Autêntica, $2015 a$.
BUTLER, Judith. Relatar a si mesmo: uma crítica à violência ética. Belo Horizonte: Autêntica, 2015b.

BUTLER, Judith. Vida precária: os poderes do luto e da violência. Belo Horizonte: Autêntica, 2019.

CÁSSIO, Fernando. Apresentação. In: CÁSSIO, Fernando (org.). Educação contra a barbárie: por escolas democráticas e a liberdade de ensinar. Belo Horizonte: Autêntica, 2019. p. 15-24.

CURY, Carlos Roberto Jamil. 0 direito à educação: direito à igualdade, direito à diferença. Cadernos de Pesquisa, São Paulo, n. 116, p. 245-262, jul. 2002. Disponível em: https://www.scielo.br/pdf/ cp/n116/14405.pdf. Acesso em: 22 jul. 2020.

FREIRE, Paulo. Pedagogia da autonomia. São Paulo: Paz e Terra, 1996.

FREIRE, Paulo. Pedagogia do oprimido. Rio de Janeiro: Paz e Terra, 1987.

FRIGOTTO, Gaudêncio. A gênese das teses do Escola sem Partido: esfinge e ovo da serpente que ameaçam a sociedade e a educação. In: FRIGOTTO, Gaudêncio. Escola "sem" Partido: esfinge que ameaça a educação e a sociedade. Rio de Janeiro: LPP, 2017. p. 17-34.

GIL, Antonio Carlos. Métodos e técnicas de pesquisa social. 6. ed. São Paulo: Atlas, 2008.

HOOKS, Bell. Educação democrática. In: CÁSSIO, Fernando (org.). Educação contra a barbárie: por escolas democráticas e a liberdade de ensinar. Belo Horizonte: Autêntica, 2019. p. 199-207.

MISKOLCI, Richard. Do desvio às diferenças. Teoria \& Pesquisa, n. 47, p. 9-41, jul./dez. 2005. Disponível em: http://www.teoriaepesquisa.ufscar. br/index.php/tp/article/view/43/36. Acesso em: 12 jun. 2020.

PARAÍSO, Marlucy Alves. Metodologias de pesquisas pós-críticas em educação e currículo: trajetórias, pressupostos, procedimentos e estratégias analíticas. In: MEYER, Dagmar Estermann; PARAÍSO, Marlucy Alves (org.). Metodologias de pesquisas pós-críticas em educação. Belo Horizonte: Mazza, 2014. p. 25-48.

PENNA, Fernando de Araujo. Discussões sobre a escola sem partido e suas repercussões no espaço escolar (lecture). In: SIMPÓSIO INTERNACIONAL DE EDUCAÇÃO SEXUAL, 5., 2017, Maringá, PR. Anais [...]. Maringá, PR: Universidade Estadual de Maringá (UEM), 2017.

RODRIGUES, Cris. Neste $1^{\circ}$ de abril, relembre nove fake news que marcaram o cenário político 
do Brasil. Brasil de Fato, São Paulo, 01 abr. 2019. Disponível em: https://www.brasildefato.com. br/2019/04/01/neste-1o-de-abril-relembre-novefake-news-que-marcaram-o-cenario-politico-dobrasil. Acesso em: 22 jul. 2020.

SILVA, Fernando G. O. da. Projeto de Pesquisa Institucional: Contribuições da interseccionalidade com as diferenças para se problematizar o saber-fazer docente (2019-2021). Jardim, MS: Universidade Estadual de Mato Grosso do Sul (UEMS), 2021.

SINGER, Helena. Gestão democrática do conhecimento: sobre propostas transformadoras da estrutura escolar e suas implicações nas trajetórias dos estudantes. Relatório de pós-doutoramento. Campinas, SP: Universidade Estadual de Campinas, 2008.

VÍDEO completo: a reunião de Bolsonaro com ministros em 22 de abril. São Paulo, 22 maio 2020. 1 vídeo (1h55min). Publicado por vejapontocom. Disponível em: https://www.youtube.com/ watch?v=nfgv7DLdCqA. Acesso em: 01 jun. 2020.

Recebido em: 24/07/2020 Aprovado em: 06/03/2021

(cc) Er-No Este é um artigo publicado em acesso aberto sob uma licença Creative Commons. 